\title{
Moderate exercise training as an effective strategy to reduce the harmful effects of cell phone radiation on Wistar rat's semen quality
}

\author{
H.A. Akbari and A.A. Gaeini* \\ Department of Exercise Physiology, Faculty of Physical Education and Sports Sciences, University of Tehran, \\ Tehran, Iran
}

\section{- Original article}

*Corresponding authors:
Abbas Ali Gaeini, PhD.,
E-mail: aagaeini@ut.ac.ir
Revised: April 2020
Accepted: June 2020
Int. J. Radiat. Res., April 2021;
19(2): 317-323
DOI: 10.29252/ijrr.19.2.317

\begin{abstract}
Background: The purpose of this study was to evaluate the impact of moderate exercise training as an effective strategy to attenuate the harmful effects of electromagnetic radiation emitted from a cell phone on Wistar Rat's semen quality. Materials and Methods: Twenty four male Wistar rats (10 weeks old) were randomly assigned to groups: control group, exercise group, radiation group, and radiation plus exercise group. The animals in radiation and radiation plus exercise groups were exposed to radiofrequency electromagnetic radiation of a cell phone 3 hours/day for 28 days. The animals in exercise and radiation plus exercise groups performed moderate exercise training six days a week for 28 days. At the same time, the control and exercise groups exposed to a mobile phone in switch off. Basic parameters of testes weight, sperm count, motility, progressivity, morphology, and viability assessed. Results: Exposure to the cell phone for 28 days significantly reduced sperm count, progressivity, and normal morphology. Exercise alone caused a significant increase in sperm progressivity only. Radiation plus exercise caused a significant increase in sperm progressivity and morphology compared with the radiation group.

Conclusion: Moderate exercise training may attenuate the harmful effects of exposure to cell phone radiation and enhance sperm quality and the fertility status of men.
\end{abstract}

Keywords: Mobile, Physical activity, Fertility, Sperm, Radiofrequency electromagnetic radiation.

\section{INTRODUCTION}

With the advent of cell phones and its increasing penetration rate, our bodies are bombarded with electromagnetic radiation more than ever, and there is no escape. It has been shown that chronic exposure to radiofrequency electromagnetic radiation (RF-EMR) emitted from cell phones leads to defective testicular function that is associated with increased oxidative stress and decreased gonadotropic hormonal profile (1). Also, in vitro and in vivo studies showed that RF-EMR exposure could negatively affect sperm quality (2). Avoiding cell phone from daily life does not seem to be feasible. Thus, a countermeasure intervention should be taken to remove or reduce these harmful effects.

It has been shown that moderate exercise can improve physical and psychological health and decrease chronic diseases (3). Moreover, moderate exercise training (MET) regulates oxidative stress enhancing cellular antioxidant defense mechanisms (4) and has a positive effect on semen quality ${ }^{(5)}$. On the other hand, intense training may reduce semen quality (6). Thus, one of the best and safest ways that may cope with these harmful effects is MET. The impact of RF-EMR emitted from cell phones on the reproductive system are currently under active 
debate, and there is no consensus on the effect of physical activity in semen quality. Positive $(7,8)$, negative $(9,10)$, and no $(11,12)$ impacts of physical activity in semen quality reported.

Therefore, the present study aimed to investigate the effect of MET as a new strategy to attenuate the harmful effects of RF-EMR emitted from a cell phone on Wistar Rat's semen quality.

\section{MATERIALS AND METHODS}

Twenty four adult male Wistar rats aged ten weeks and weighing $200 \pm 10$ g were purchased from the Laboratory Animal Farm and Accessories (Tehran, Iran). Then, the animals were housed in polycarbonate cages inside a well-ventilated room kept throughout the study on a 12-h light/12-h dark cycle (from 8:00 a.m. to 8:00 p.m., the lights were off, and from 8:00 p.m. to 8:00 a.m., the lights were on) at an average temperature of $24 \pm 2 \quad{ }^{\circ} \mathrm{C}, \quad 40-50 \%$ humidity, with a standardized regular diet and water ad libitum. All procedures performed in studies involving animals were following the ethical standards of the institution or practice at which the studies were conducted (Animal Care and Ethics Committee of Sport Sciences Research Institute of Iran, IR.SSRI.REC.1397.376). All efforts were made to minimize the suffering of animals during exercise training protocols.

Then, the animals randomly assigned into four groups (6 rats each group): control group $(C)$, radiation group $(R)$, exercise group (E), and radiation plus exercise group $(\mathrm{R}+\mathrm{E})$. Before starting the experiment, all rats acclimatized with the laboratory environment and $\mathrm{E}$ and $\mathrm{R}+\mathrm{E}$ groups familiarized with treadmill and $\mathrm{R}$ and $\mathrm{R}+\mathrm{E}$ groups exposed to a cell phone in off mode for one week (table 1). In week 3 , one of the rats in the $\mathrm{R}+\mathrm{E}$ group refused to run on the treadmill and was set aside from the experiment $(\mathrm{R}+\mathrm{E} ; \mathrm{n}=$ 5).

In the present study, we used a cell phone described in a previous study (1). The cell phone used was Nokia 105- Dual-band EGSM900/1.800 MHz. From previous studies, we found that 3 hours per day for 28 days of RF-EMR exposure can negatively affect semen quality of male Wistar rats $(1,13)$. So, we exposed $\mathrm{R}$, and $\mathrm{R}+\mathrm{E}$ groups to RF-EMR emitted from the cell phone in active mode for 3 hours continuously per day for 28 days (exposure time was between 7.00 a.m. and 10.00 a.m.). $\mathrm{R}$ and $\mathrm{R}+\mathrm{E}$ groups were placed in smaller cages to prevent them from moving away. To minimize the heat effects of the phone; the phone kept out of the cages at a distance of $10-20 \mathrm{~cm}$ from the rats. Animals were free to move inside the cage during radiation exposure. Simultaneously, C and E groups exposed to the cell phone in switch Off mode in the same cages and a separate room.

Our exercise training protocol was almost similar to study of Salim et al. (14). In this protocol, E and R+E groups performed MET six days a week throughout the study (Saturday to Thursday). Table 2 shows the exercise training protocol.

Table 1. The familiarization protocol for exercise and radiation exposure groups.

\begin{tabular}{|c|c|c|c|}
\hline & \multicolumn{2}{|c|}{ Exercise training } & $\begin{array}{c}\text { Exposure to } \\
\text { Radiation }\end{array}$ \\
\hline Days & $\begin{array}{c}\text { Duration } \\
\text { (minutes) }\end{array}$ & $\begin{array}{c}\text { Intensity (meter/ } \\
\text { minute) }\end{array}$ & $\begin{array}{c}\text { Duration } \\
\text { (hours) }\end{array}$ \\
\hline $1-2$ & 5 & 5 & 1 \\
\hline $3-4$ & 10 & 10 & 2 \\
\hline $5-6$ & 15 & 15 & 3 \\
\hline
\end{tabular}

Table 2. Exercise training protocol.

\begin{tabular}{|c|c|c|}
\hline Week 1 & $\begin{array}{c}\text { Duration } \\
\text { (minutes) }\end{array}$ & $\begin{array}{c}\text { Intensity (meter/ } \\
\text { minute) }\end{array}$ \\
\hline Warm-up & 3 & $\begin{array}{c}\text { an increase from 0 to } \\
15\end{array}$ \\
\hline Running & 15 & 15 \\
\hline Active rest (walking) & 5 & 5 \\
\hline Running & 15 & 15 \\
\hline Cooldown & 3 & a decrease from 15 to 0 \\
\hline Week 2, 3, 4 & & an increase from 0 to \\
\hline Warm-up & 3 & 15 \\
\hline Running & 30 & 15 \\
\hline Active rest (walking) & 5 & 15 \\
\hline Running & 30 & a decrease from 15 to 0 \\
\hline Cooldown & 3 &
\end{tabular}

Int. J. Radiat. Res., Vol. 19 No. 2, April 2021 
At the end of the study, all rats asphyxiated with $\mathrm{CO}_{2}$. The abdominal cavity was opened up through a lower transverse abdominal, and the testes with epididymis were excised, blotted, and weighed immediately. Then, right caudal epididymis separated from the testis, and the semen was collected, allowed to incubate (Memmert, model: INB400, Germany) in buffer containing BSA at $37{ }^{\circ} \mathrm{C}$ for 30 minutes. Light microscopy (Olympus, model BX51, Japan) and Sperm Chamber used for sperm movement analysis. The left caudal epididymis was cut up with anatomic scissors and diluted to $0.5 \mathrm{~mL}$ with a Tris buffer solution. A slide placed on the light microscope, an aliquot of this solution was on the slide, and percentage motility was evaluated visually at a magnification of $\times 400$. progressively motile sperm were defined as the number of progressively motile sperm/ total number of sperm $\times 100$. The percentage motile sperm, which is the number of motile sperm/ total number of sperm $\times 100$, assessed manually so that an expert counted the number of stationary sperm in the sample, then fixed the sample and counted the total number of sperm. Caudal sperm was taken from the original dilution for motility and diluted 1:20 with 10\% neutral buffered formalin. For morphological abnormalities, five hundred sperms from the sample scored. Briefly, in wet preparations using phase-contrast optics, spermatozoa were categorized. In this study, a spermatozoon considered abnormal if it had one or more of the following features: rudimentary tail, round head, and detached head and expressed as a percentage of morphologically normal sperm. The data presented as a percentage of morphologically normal sperm. Viability of spermatozoa examined by the supravital staining method (15). Briefly, a drop of sperm suspension was placed on a spot plate and mixed with one drop of $1 \%$ aqueous eosin $Y$ solution. After 15 seconds, two drops of $10 \%$ aqueous nigrosine solution was added and mixed. A drop of this mixture put on a glass slide. A thin smear made and then air-dried. The smears examined with 100 oil magnification. Live sperm cells appear white and dead sperms pink. At least 300 spermatozoa counted, and the result expressed as the percentage of live sperm.

Statistical analysis was performed with SPSS software (version 23). Shapiro-Wilk test was used to determine the normal distribution. One-way analysis of variance (ANOVA) was used to compare the mean values of variables among the groups. Tukey's post hoc test was used to identify the significance of pairwise comparison of mean values among the four groups. The p-value of less than 0.05 was statistically considered significant.

\section{RESULTS}

The weights of the right and left testes remained unchanged in all the experimental groups $(E, R$, and $R+E)$ when compared with the C group ( $p>0.05$ ) (table 3 ). The sperm count was increased significantly in the $E$ group when compared with the $\mathrm{R}$ and $\mathrm{R}+\mathrm{E}$ groups $(\mathrm{p}<0.05)$. However, the sperm count was decreased dramatically in $\mathrm{R}$ and $\mathrm{R}+\mathrm{E}$ groups when compared with the $C$ group $(\mathrm{p}<0.05)$ (table 3$)$. The viability ratio remained unchanged in all the experimental groups when compared with the $\mathrm{C}$ group ( $p>0.05$ ) (table 3 ). The sperm motility was increased significantly in the E group when compared with the R group $(\mathrm{p}<0.05)$ (table 3$)$. The sperm progressivity was decreased dramatically in the $\mathrm{R}$ group when compared with $C$ and $R+E$ groups $(p<0.05)$. However, the sperm progressivity was significantly increased in the E group when compared with $\mathrm{R}, \mathrm{C}$, and $R+E$ groups $(p<0.05) \quad($ table 3$)$. The normal sperm morphology was decreased significantly in $\mathrm{R}$ and $\mathrm{R}+\mathrm{E}$ groups when compared with the $\mathrm{C}$ group $(p<0.05)$. However, it was increased significantly in $E$ and $R+E$ groups when compared with the $\mathrm{R}$ group $(\mathrm{p}<0.05)$. Besides, the normal sperm morphology was increased significantly in the E group when compared with the $\mathrm{R}+\mathrm{E}$ group $(\mathrm{p}<0.05)$ (table 3$)$. 
Akbari and Gaeini / Effect of exercise and radiation on semen quality

Table 3. Effects of Radiation, Exercise, and Radiation + Exercise (Combined) groups on the criteria of sperm fertility potential.

\begin{tabular}{|c|c|c|c|c|}
\hline Parameters & Control $(n=6)$ & Exercise $(n=6)$ & Radiation ( $n=6$ ) & Combined $(n=5)$ \\
\hline Left testis (g) & $1.68 \pm 0.13$ & $1.67 \pm 0.18$ & $1.70 \pm 0.14$ & $1.70 \pm 0.27$ \\
\hline Right testis (g) & $1.66 \pm 0.13$ & $1.65 \pm 0.17$ & $1.67 \pm 0.14$ & $1.56 \pm 0.2$ \\
\hline Sperm count $\left(\times 10^{6} / \mathrm{ml}\right)$ & $58.91 \pm 5.38$ & $51.75 \pm 11.65+\ddagger$ & $38.66 \pm 5.58^{*}$ & $37.00 \pm 5.96^{*}$ \\
\hline Viability ratio (\%) & $97.16 \pm 1.47$ & $97.33 \pm 1.21$ & $97.50 \pm 1.04$ & $97.60 \pm 1.14$ \\
\hline Sperm motility (\%) & $61.66 \pm 11.25$ & $76.66 \pm 8.16 \ddagger$ & $51.66 \pm 14.37$ & $64 \pm 16.73$ \\
\hline Sperm progressivity (\%) & $66.66 \pm 16.66$ & $85.33 \pm 7.11 * \ddagger \dagger$ & $42.50 \pm 10.36^{*}$ & $65 \pm 13.69 * \ddagger$ \\
\hline Sperm morphology (\% normal) & $80.83 \pm 9.17$ & $80 \pm 6.23+\ddagger$ & $50.83 \pm 5.84^{*}$ & $64 \pm 4.18 * \ddagger$ \\
\hline \multicolumn{5}{|c|}{$\begin{array}{l}\text { ata are expressed as means } \pm \text { standard deviation. Data were analyzed by one-way ANOVA, followed by Tukey's post hoc test. } \\
\text { * Significant different in compared with the control group, } p<0.05 \\
\text { I Significant different in compared with the radiation group, } p<0.05 \\
+ \text { Significant different in compared with the combined group, } p<0.05\end{array}$} \\
\hline
\end{tabular}

\section{DISCUSSION}

To the best of our knowledge, this is the first study that investigated the effect of moderate aerobic exercise training to reduce the adverse effects of the RF-EMR emitted from a cell phone on semen quality in male Wistar Rats.

We showed that 3 hours/day for 28 days of radiation emitted from the cell phone led to a significant decrease in sperm count, progressivity and normal morphology which are among the critical parameters that affect the chance of conceiving, and had little effect on testes weight, sperm viability, and motility. The present result is mostly similar to previous similar studies. Four weeks of exposure of male Wistar rats to the same cell phone showed that 3 hours of continuous exposure to RF-EMR caused a significant decrease in sperm count, normal morphology, and progressivity. Also, one-hour exposure caused a significant reduction in sperm progressivity, which means that sperm progressivity is the most sensitive parameter that decreases even in short duration of RF-RMR exposure (1). One hour per day for 28 days, exposure of male Wistar rats to RF-EMR emitted from a cell phone reduced motile sperm by approximately $40 \%$ (13). Also, pooled results from in vitro and in vivo studies indicated that cell phone exposure negatively affects sperm quality by reducing sperm count, motility, morphology, and viability, which are the parameters most frequently used in the clinical settings to assess fertility $(2,16)$. Similarly, in humans, it has been shown that continuous use of cell phones is linked with decreased motility, sperm concentration, morphology, and viability (17).

Altogether, These results suggest that RF-EMR exposure can impair male fertility, and the severity of the effects of RF-EMR emitted from a cell phone on semen quality depends on wave frequency, intensity, exposure length, distance from the source of radiation, and method of administration.

To date, the exact mechanism of action of RF-EMR on reproductive organs, and thereby the fertility pattern, is unknown (2), but some possible mechanisms have been developed. Exposure to RF-EMR can damage biological tissues and induces malicious changes. Thermal and non-thermal mechanisms can explain these changes. The thermal effects of RF-EMR can occur by absorption of the heat by the body and are associated with the specific absorption rate (SAR). SAR is the amount of energy (heat) that transferred to the material, which varies from 0.12 to 1.6 watts $/ \mathrm{kg}$ of body weight (18). The interaction between RF-EMR and living tissues can increase temperature. In the present study, we excluded the temperature effect by keeping the phone out of the cages at a distance of 10-20 $\mathrm{cm}$ from the rats to minimize the heat effects of the phone. Besides, Modern cell phones are typically well below these thresholds (SAR $<1.6$ $\mathrm{W} / \mathrm{kg}$ ), whereas SAR $>4 \mathrm{~W} / \mathrm{kg}$ has an adverse heating effect on semen quality (19).

The plausible mechanism of non-thermal effects of RF-EMR on biological tissues has not yet fully elucidated and needs to be discussed. Superficial tissues such as skin absorb the non-thermal radiations. These radiations are 
associated with changes in the tissues in association with the amount of energy absorbed. Most of the studies revealed that the non-thermal effects of RF-EMR that affect semen quality are associated with an increase in free radical production in tissues. This effect mediates by reactive oxygen species (ROS). ROS, which is crucial for spermatogenesis, plays a functional role in sperm capacitation, the acrosome reaction, and binding to the oocyte (20). The plasma membrane of spermatozoa has a high concentration of polyunsaturated fatty acids, which are essential for many spermatic functions but also have a role in the production of ROS (21). RF-EMR emitted from a cell phone can increase ROS production by enhancing the activity of nicotinamide adenine dinucleotide (NADH) oxidase in the cell membrane (22). Three hours'/day exposure to RF-EMR emitted from a cell phone for 28 days led to a significant increase in circulating oxidative stress marker Malondialdehyde (MDA), and a substantial decrease in the level of circulating antioxidant enzyme Superoxide dismutase (SOD) that suggest a decline in sperm antioxidant capacity (1). So it can be inferred that RF-EMR emitted from a cell phone can increase oxidative stress and decrease antioxidant capacity. Also, ROS can cause DNA damage (23). There is an association between oxidative stress and DNA fragmentation in male infertility and DNA damage reduction with antioxidant therapy (24).

Also, the present study showed that moderate aerobic treadmill exercise training alone by inducing a remarkable increase in sperm progressivity affects semen quality positively. Therefore, the MET protocol used in the present study may influence semen quality. The results of the studies that investigated the impact of exercise training on semen quality are contradictory because the types, intensities, and durations of them are different $(6,25)$. The effects of MET on Wistar rat's semen quality has been poorly documented. Nevertheless, most of the studies revealed that recreational and moderate aerobic exercise activity could increase semen quality $(5,26)$, and intense and elite physical activity could have a detrimental effect on semen quality and, therefore, male fertility $(5,27)$.
12 and 24 weeks moderate-intensity continuous training (walking or jogging on a treadmill 25-30 min/day, 3-4 days/week and then increased to $40-45 \mathrm{~min} /$ day during the last 12 weeks) significantly increased progressive motility, sperm morphology, and sperm concentration (25).

When the exercise added to RF-EMR exposure from the cell phone, sperm progressivity increased significantly, and normal morphology improved remarkably (but still had a significant difference with $\mathrm{C}$ group). To the best of our knowledge, there is no similar study that can be compared with these results. Thus, we can conclude that moderate treadmill exercise training can prevent decreasing semen quality due to cell phone radiation exposure.

The exact mechanism of the exercise training on semen quality is unclear, but it seems that oxidative stress and hormonal changes can play a potential role (28). Our MET protocol is an antioxidant $(14,29)$ and may decrease MDA $(30)$, increase SOD (31), and reduce sperm DNA damage (32). Therefore, it seems that this type of MET may confront with harmful effects of exposure to RF-EMR emitted from the cell phone on semen quality by upregulating antioxidant genes. These effects, which can affect semen quality, may occur by hormonal changes (1). Nevertheless, concerning MET, results of the many studies assessing hormonal behavior are contradictory, and for extracting any conclusion about hormonal changes due to MET that led to reducing the harmful effects of cell phone radiation on semen quality, more studies are needed.

\section{CONCLUSION}

Exposure to RF-EMR emitted from the cell phone for 3 hours per day for 28 days does affect semen quality and fertility of male Wistar rats adversely. Also, MET may attenuate the harmful effects of RF-EMR emitted from the cell phone on Wistar rat's semen quality. Therefore, MET might have a beneficial impact that could be of interest to improve the sperm quality and fertility and prevent the potential adverse 
effects of exposure to RF-EMR. We speculate that keeping a mobile phone near the testes may reduce male fertility, and MET may attenuate these impairments.

\section{Conflicts of interest: Declared none.}

\section{REFERENCES}

1. Oyewopo A, Olaniyi S, Oyewopo C, Jimoh AJA (2017) Radiofrequency electromagnetic radiation from cell phone causes defective testicular function in male Wistar rats. Andrologia 49(10): e12772.

2. Kesari KK, Agarwal A, Henkel R (2018) Radiations and male fertility. Reproductive Biology and Endocrinology. 16(1): 118.

3. Chang P-S, Knobf T, Oh B, Funk M (2019) Physical and psychological health outcomes of qigong exercise in older adults: A systematic review and meta-analysis. The American J of Chinese Medicine, 47(02): 301-22.

4. Kruk J, Aboul-Enein HY, Kładna A, Bowser JE (2019) Oxidative stress in biological systems and its relation with pathophysiological functions: the effect of physical activity on cellular redox homeostasis. Free Radical Research, 53(5): 497-521.

5. Ibañez-Perez J, Santos-Zorrozua B, Lopez-Lopez E, Matorras R, Garcia-Orad A (2019) An update on the implication of physical activity on semen quality: a systematic review and meta-analysis. Archives of Gynecology and Obstetrics. 299(4): 901-921.

6. Jóźków P and Rossato M (2017) The impact of intense exercise on semen quality. American J of Men's Health, 11 (3): 654-62.

7. Maleki BH and Tartibian B (2017) High-Intensity exercise training for improving reproductive function in infertile patients: A randomized controlled trial. J Obstet Gynaecol $\mathrm{Ca}$, 39(7): 545-58.

8. Gaskins AJ, Mendiola J, Afeiche M, Jørgensen N, Swan SH, Chavarro JE (2015) Physical activity and television watching in relation to semen quality in young men. British Journal of Sports Medicine, 49(4): 265-70.

9. Vaamonde D, Da Silva ME, Poblador MS, Lancho JL (2006) Reproductive profile of physically active men after exhaustive endurance exercise. International Journal of Sports Medicine, 27(9): 680-9.

10. Vaamonde D, Da Silva-Grigoletto ME, García-Manso JM, Vaamonde-Lemos R, Swanson RJ, Oehninger SC (2009) Response of semen parameters to three training modalities. Fertility and Sterility, 92(6): 1941-6.

11. Mínguez-Alarcón L, Chavarro JE, Mendiola J, Gaskins AJ, Torres-Cantero AM (2014) Physical activity is not related to semen quality in young healthy men. Fertility and Sterility, 102(4): 1103-9.
12. Jóźków $P$, Mędraś $M$, Lwow $F$, Zagrodna A, SłowińskaLisowska M (2017) Associations between physical activity and semen quality in young healthy men. Fertility and Sterility, 107(2): 373-8.e2.

13. Mailankot $M$, Kunnath $A P$, Jayalekshmi $H$, Koduru $B$, Valsalan R (2009) Radio frequency electromagnetic radiation (RF-EMR) from GSM $(0.9 / 1.8 \mathrm{GHz})$ mobile phones induces oxidative stress and reduces sperm motility in rats. Clinics (Sao Paulo, Brazil), 64(6): 561-5.

14. Salim S, Sarraj N, Taneja M, Saha K, Tejada-Simon MV, Chugh GJBbr (2010) Moderate treadmill exercise prevents oxidative stress-induced anxiety-like behavior in rats. Behavioural Brain Research, 208(2): 545-52.

15. Eliasson R (1977) Supravital staining of human spermatozoa. Fertility and Sterility, 28(11): 1257.

16. Adams JA, Galloway TS, Mondal D, Esteves SC, Mathews FJEi (2014) Effect of mobile telephones on sperm quality: a systematic review and meta-analysis. Environment International, 70: 106-12.

17. Agarwal A, Deepinder F, Sharma RK, Ranga G, Li J (2008) Effect of cell phone usage on semen analysis in men attending infertility clinic: an observational study. Fertility and Sterility, 89(1): 124-8.

18. La Vignera S, Condorelli RA, Vicari E, D'Agata R, Calogero $A E$ (2012) Effects of the exposure to mobile phones on male reproduction: a review of the literature. Journal of Andrology, 33(3): 350-6.

19. Aitken RJ, Bennetts LE, Sawyer D, Wiklendt AM, King BVJIjoa (2005) Impact of radio frequency electromagnetic radiation on DNA integrity in the male germline. Int J Androl, 28(3): 171-9.

20. Garrido N, Meseguer M, Alvarez J, Simón C, Pellicer A, Remohí J (2004) Relationship among standard semen parameters, glutathione peroxidase/glutathione reductase activity, and mRNA expression and reduced glutathione content in ejaculated spermatozoa from fertile and infertile men. Fertility and Sterility, 82: 1059-66.

21. Cotgreave (2005) Biological stress responses to radio frequency electromagnetic radiation: are mobile phones really so (heat) shocking? Arch Biochem Biophys, 435(1): 227-40.

22. Yahyazadeh A, Deniz ÖG, Kaplan AA, Altun G, Yurt KK, Davis DJ (2018) The genomic effects of cell phone exposure on the reproductive system. Environ Res, 167: 68493.

23. Bui A, Sharma R, Henkel R, Agarwal A (2018J) Reactive oxygen species impact on sperm DNA and its role in male infertility. Andrologia, 50(8): e13012.

24. Agarwal A and Majzoub A (2017) Role of antioxidants in assisted reproductive techniques. World J Mens Health, 35 (2): 77-93.

25. Maleki BH, Tartibian B, Chehrazi M (2017) The effects of three different exercise modalities on markers of male reproduction in healthy subjects: a randomized controlled trial. Reproduction, 153(2): 157-74.

26. Maleki BH and Tartibian B (2017) Moderate aerobic exercise training for improving reproductive function in infer- 
tile patients: a randomized controlled trial. Cytokine, 92: 55-67.

27. Hayden RP, Flannigan R, Schlegel PN (2018) The role of lifestyle in male infertility: diet, physical activity, and body habitus. Current Urology Reports, 19(7): 56.

28. Du Plessis SS, Agarwal A, Sabanegh Jr ES (2014) Male infertility: a complete guide to lifestyle and environmental factors. USA: Springer, E-book.

29. Gomez-Cabrera M-C, Domenech E, Viña J (2008) Moderate exercise is an antioxidant: upregulation of antioxidant genes by training. Free Radic Biol Med, 44(2): 126-31.
30. Alessio HM and Goldfarb AH (1988). Lipid peroxidation and scavenger enzymes during exercise: adaptive response to training. J Appl Physiol, 64(4): 1333-6.

31. Choi EY and Cho YO (2007)The effects of physical training on antioxidative status under exercise-induced oxidative stress. Nutr Res Pract, 1(1): 14-8.

32. Palmer NO, Bakos HW, Owens JA, Setchell BP, Lane MC (2012) Diet and exercise in an obese mouse fed a high fat diet improves metabolic health and reverses perturbed sperm function. Am J Physiol Endocrinol Metab, 302(7): E768-80. 
